\title{
Implications of Consumer Animosity for Marketing Strategy: An Abstract
}

\author{
Olga Kvasova and Sergii Tokar
}

\begin{abstract}
Company sales often suffer as a consequence of consumer animosity. Despite a significant number of studies on the antecedents of consumer antipathy, the effect of personality traits has never been examined. Meanwhile, just as the scholars have tested alternative antecedents of animosity, evolvement of the trait theory revealed that another important predictor of behaviour is personality. In this light, our study looks at the animosity of Ukrainian consumers towards Russia and aims to (1) identify personality drivers and behavioural outcomes of consumer animosity and (2) examine the moderating effects of key socio-demographic variables (gender, age, education, income, religion) on the link between animosity and product avoidance. Structural equation modelling indicated that neuroticism and openness are positively associated with animosity, while extraversion and conscientiousness have a negative effect on this feeling. Besides, animosity was found to influence purchase behaviour. Finally, certain socio-demographic characteristics, namely, gender, age, education and religion had a moderating effect on the link between consumer animosity and product avoidance. Marketing implications, limitations and future research avenues are provided.
\end{abstract}

References Available Upon Request

O. Kvasova $(\bowtie) \cdot$ S. Tokar

University of Central Lancashire, Larnaca, Cyprus

e-mail: okvasova@uclan.ac.uk; stokar@uclan.ac.uk 